\title{
DETERMINATION OF OPTIMAL PRODUCTION PROCESS USING SCHEDULING AND SIMULATION SOFTWARE
}

\author{
Duplakova, D. ; Teliskova, M.; Duplak, J.; Torok, J.; Hatala, M.; Steranka, J. \& Radchenko, S. \\ Technical University of Kosice, Faculty of Manufacturing Technologies with a seat in Presov, \\ Bayerova 1, 08001 Presov, Slovakia \\ E-Mail: darina.duplakova@tuke.sk (" Corresponding author)
}

\begin{abstract}
The objective of the article is to present the linking of simulation and planning software. The paper begins with a review of recent literature as well as description of the problem under investigation. Following from practical requirements, five decision-making rules were implemented to the production process. In the final part, the overall results to ensure time and economic efficiency of the production process are presented. The obtained results show that the best option is to apply the rule during which the first part to be machined is the one that first enters the production process to ensure minimum production time, maximum machine load and limit machine costs. By application of this rule, the total production time accounts for 524 seconds at the total cost of $7914.60 €$. The overall benefits of the research are being described in details in the final part of the article.

(Received in April 2018, accepted in July 2018. This paper was with the authors 1 week for 1 revision.)
\end{abstract}

Key Words: Simulation Software, Scheduling Software, Time Efficiency, Economic Efficiency

\section{INTRODUCTION}

Nowadays, simulation software is being widely used in various industries. Simulation tools are applied in construction industry, mining industry, electrical engineering, automotive industry and general engineering. In engineering and automotive industry, simulation tools can be applied to production and auxiliary processes, logistics, planning, construction, management, etc. Logistics, planning and management are the areas in which simulation tools are used very often. Various supporting planning and simulation tools are used in this field to ensure optimal running of the production process both technically and economically. For this reason, it is necessary to focus the research activities on the issue within the scientific community. It is generally known that optimization ensures economic and logistic efficiency of production necessary for the smooth running of each manufacturing enterprise. Due to the large number of simulation tools that can be used in manufacturing plants, Rashidi describes six basic taxonomies as well as compares over 60 simulation tools in the taxonomies [1]. A large number of existing studies in the broader literature have examined the issue of material flow planning and simulation. In 2014, the Journal of System and Software released the publication which provided an overview of the research carried out in the area of industrial application of simulation tools [2]. In 1997, modern Witness simulation tool was presented and described at the Atlanta Conference. This tool was applied to various optimization processes [3]. In 2011, Witness Simulation Tool was used to solve logistics problems in automotive components manufacturing. The solution to the problem was to optimize planning and layout of the existing system followed by the general conclusion as well as recommendation for small and medium-sized enterprises aimed at automotive components production [4]. In 2012, optimization of the parameters of the Kanban production system focusing on the assembly site using this simulation tool was resolved [5].

In 2013, the wide-scale application of this simulation tool was proved. Witness simulation tool was used to create a universal simulation model for verification and subsequent optimization of handling devices using basic heuristic optimization methods [6]. In 2014, the 
authors Chen et al. utilized the simulation tool to shorten production cycles in developing a new product [7], and a year later, Dyntar and Strachotova applied this tool to design and optimize the supply chain [8]. In 2016, research on using Witness program was aimed at improving material flow continuity [9], planning and layout optimization [10] etc. The literature review shows that the application of the simulation tool is used not only in industries but it is possible to apply Witness simulation tool to education process. The authors Cotet et al. utilized CAD simulation and material flow simulation to create a platform for educational purposes. Developing the platform enabled to identify and remove bottlenecks to ensure high efficiency [11]. In 2017, Witness was used to solve the optimization of the assembly line balancing in GA [12] based production as well as to improve productivity in a small manufacturing enterprise [13]. In addition to the simulation tool used to optimize material flow, various planning software programs are used in common practice to ensure time and economic efficiency. A more comprehensive description can be found in the study aiming at optimizing time structures using Lekin scheduling software. Using Gantt charts, the authors set the optimal material flow arrangement to ensure time efficiency [14]. In 2017, Forrai and Kulcsar issued the publication dedicated to the creation of the new planning software to support automotive production focusing on creating plans to implement manufacturing activities that meet customer requirements [15]. As has been previously reported in the literature, planning issues can be applied in various simulation tools. The authors bring some more information about the use of hybrid metaheuristic algorithm for job shop scheduling problem in cooperation for subsequent verification with simulation tools Simio and Autodesk Factory Design Suite [16]. Recent study by Coman and Burian concluded that planning issues can also be addressed by using WinQSB and Lekin software programs [17]. It is important to note that the issue of simulation tools and planning is applicable not only in the field of material flow planning but also in ensuring economic efficiency. A recent study by Gracanin et al. reviewed the impact of job shop scheduling on value stream optimization and decreasing of cost-time investment [18]. It was reported in the literature that the wide variety of simulation and scheduling software programs are used separately. As far as we know, no previous research has investigated the issue of linking simulation and planning software programs including the verification of its results. The idea of linking both simulation and scheduling programs was based on a requirement to ensure an optimal production process when taking into account both time and economic aspects.

\section{MATERIAL AND METHODS}

Two software programs - Lekin planning program and Witness simulation program were applied in the research. The input values of the production times of inner rings, which are part of the rolling bearings ( $\mathrm{P} 1-\mathrm{P} 4)$, were obtained from the practice. Specific quantitative data is shown in Table I. The columns represent the individual manufacturing operations and the rows include the manufactured components. Values are given in seconds. Fig. 1 below the input values table shows the material flow. To meet the practical requirements, preference was given to individual component machining. The parts are suitable to be machined in the following order: P1, P2, P3, and P4.

Lekin Planning Software was used to create optimal ordering for individual component machining using Gantt Charts. Job shop planning was chosen for the appearance of the given production process. The $n \times m$ minimum-makespan general job-shop scheduling problem can be described by a set of $n$ jobs $\left\{J_{i}\right\}(1 \leq j \leq n)$ which is to be processed on a set of $m$ machines $\left\{M_{r}\right\}(1 \leq r \leq m)$. Each job has a technological sequence of machines to be processed [19]. 
Table I: Input data.

\begin{tabular}{|l|c|c|c|c|}
\hline Operation & $\mathrm{P} 1[\mathrm{~s}]$ & $\mathrm{P} 2[\mathrm{~s}]$ & $\mathrm{P} 3[\mathrm{~s}]$ & $\mathrm{P} 4[\mathrm{~s}]$ \\
\hline Grinding 1 & - & 3 & 21 & 3 \\
\hline Roughing 1 & 26 & - & - & - \\
\hline Chamfering & 3 & - & 14 & 4 \\
\hline Roughing 2 & - & 15 & 17 & 16 \\
\hline Turning & 3 & - & - & - \\
\hline Grinding 2 & - & 4 & 43 & 47 \\
\hline Grinding 3 & - & - & 37 & 38 \\
\hline Grinding 4 & - & - & - & 49 \\
\hline Burnishing & 30 & 44 & 41 & 55 \\
\hline Markings & 12 & 22 & 45 & 18 \\
\hline Cleaning 1 & 30 & 30 & 30 & 30 \\
\hline Final degreasing & 7 & 3 & 3 & 3 \\
\hline Cleaning 2 & 30 & 30 & 30 & 30 \\
\hline Transport & 107 & 96 & 125 & 133 \\
\hline
\end{tabular}

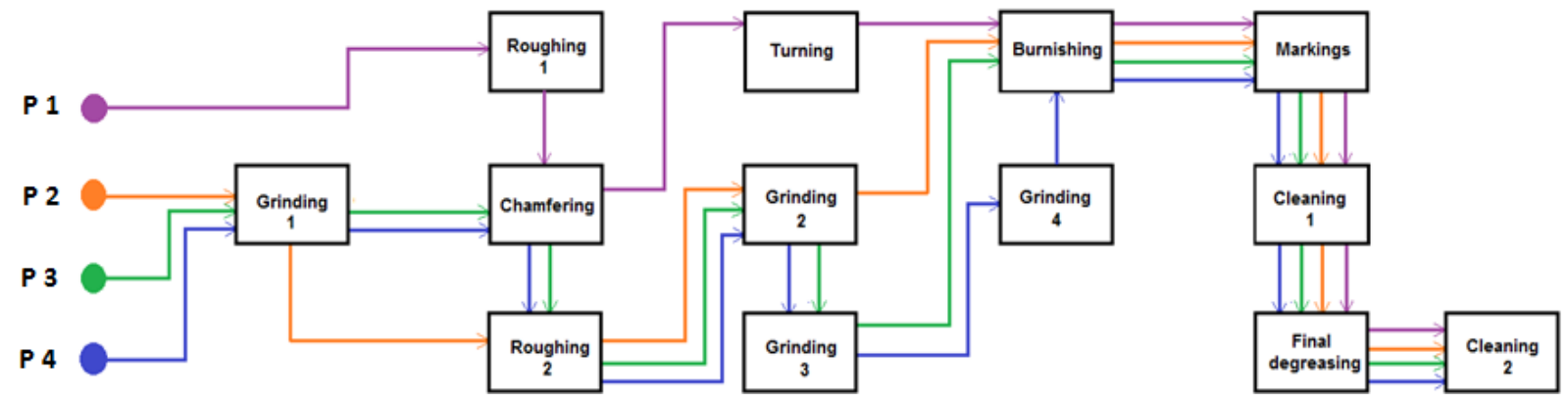

Figure 1: Material flow.

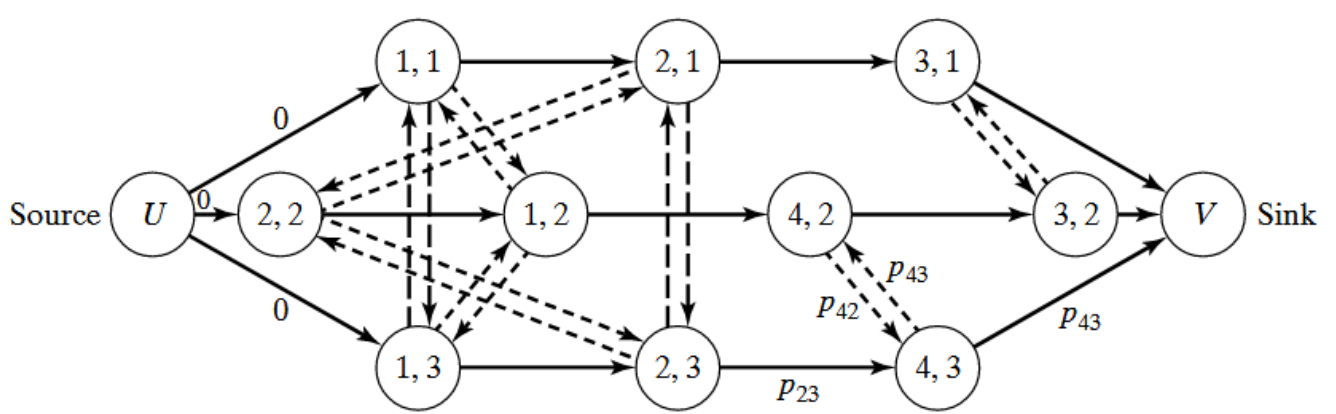

Figure 2: Example of a directed graph for job shop with makespan as objective [20].

For this type of planning, five heuristic rules were applied to create an optimal production process considering the practical requirements. These rules are the part of Lekin program. In each mathematical expression of the rules, the following notations are used:

$N(t)$ - a set of waiting jobs at time $t$

$r_{j} \quad-$ release date of job $j \in N(t)$

$d_{j} \quad-$ due date of job $j \in N(t)$

$w_{j} \quad$-importance factor (or weight) of job $j \in N(t)$

$v_{j} \quad$ - remaining processing time of job $j \in N(t)\left(0 \leq v_{j}(t) \leq p_{j}\right)$

$p_{q j}^{\prime} \quad$ - processing time of the operation of job $j$, which corresponds to a certain $p_{i j}$ value according to the machine $I$ on which operation $q$ is to be processed.

The following dispatching rules are to be used:

1. The shortest processing time rule (SPT) generates an optimal schedule for a single machine scheduling problem which minimizes the total completion time. The priority index $I_{j}$ of job $j$ is defined by: 


$$
I_{j}=\frac{1}{p_{j}}
$$

2. First Come - First Served (FCFS) - the jobs are fulfilled in arrival order to manufacturing process. This rule arranges the jobs in $N(t)$ in non-decreasing order of $r_{j}$. The priority index $I_{j}$ of job $j$ is defined by:

$$
I_{j}=\frac{1}{r_{j}}
$$

3. Minimum slack rule (MS) is usable in manufacturing planning for minimization of idle time between workstations. The main principle consists in job preference with the higher processing demand by slack time. The priority index $I_{j}$ of job $j$ is defined by:

$$
I_{j}=\frac{1}{\left(d_{j}-v_{j}(t)-t\right)}
$$

4. Critical Ratio rule $(\mathrm{CR})$ - in practice, a job is critical if the slack time is relatively small and its importance factor $\left(w_{j}\right)$ is relatively large. The priority index $I_{j}(t)$ of job $j\left(d_{j}>t\right)$ is defined by:

$$
I_{j}(t)=\frac{w_{j}}{\left(d_{j}-t\right)}
$$

5. Longest processing time rule (LPT) - preferred operation of part with the longest cycle time. The priority index $I_{j}$ of job $j$ is defined by:

$$
\max I_{j}=p_{q j}^{\prime}
$$

In the second part of the experiment, Witness software was used to verify the decisionmaking rules as well as to determine the optimal organization of the production process not only in terms of time efficiency but also in terms of its economic efficiency. Based on material flow that is described above, a basic model has been developed using Witness software which was subsequently modified on the basis of time-based optimization in Lekin scheduling program. Fig. 3 shows the simulation model.

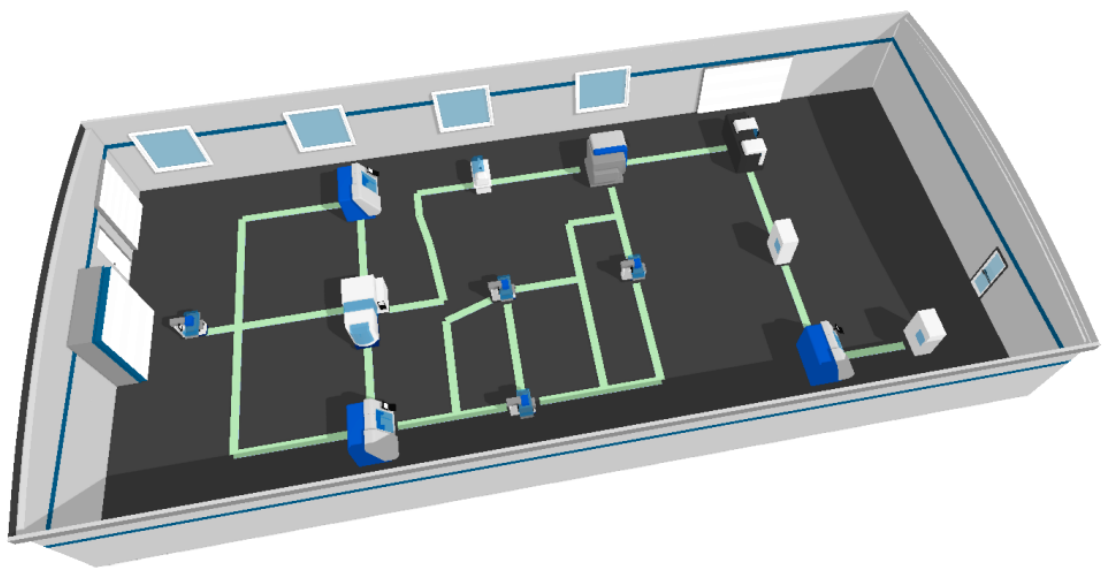

Figure 3: Model of production process - Witness software.

\section{APPLICATION OF SCHEDULING SOFTWARE LEKIN AND SIMULATION SOFTWARE WITNESS}

Based on the input data, five Gantt charts were created with the descriptions of the arrangements. In individual arrangements and evaluations, it is necessary to focus on the following variables: 
- The Makespan $\left(C_{\max }\right)$ - the maximum job completion time. A job's completion time $C_{j}$ is the time it finishes its processing under a given schedule.

- The Maximum Tardiness $\left(T_{\max }\right)$. A job's tardiness $T_{j}$ is the positive part of the difference between its completion time $C_{j}$ and its due date $d_{j}: T_{j}=\left(C_{j}-d_{j}\right)$. For each job $j, U_{j}$ is defined as an indicator of its lateness: $U_{j}=1$ if job $j$ is late, and 0 otherwise.

- The Total Number of Late Jobs $\left(\Sigma U_{j}\right)$.

- The Total Flow Time $\left(\Sigma C_{j}\right)$ - the sum of job completion times.

When applying the SPT rule, care must be taken to minimize production time. Fig. 4 provides a basic Gantt chart with individual sequences and operations that meet the requirement to minimize production time. The total $C_{\max }$ production time in this case reached 543 seconds with a total $T_{\max }$ delay of 117 seconds. In a Gannt chart we can see the order of individual component processing, where P1 and P2 are the first components to leave the warehouse to be machined in the production process. In this case, on each machine, the last component to be machined is $\mathrm{P} 4$ which also exits the overall production process as the last one. When applying the SPT rule, a total of three late jobs, was recorded.

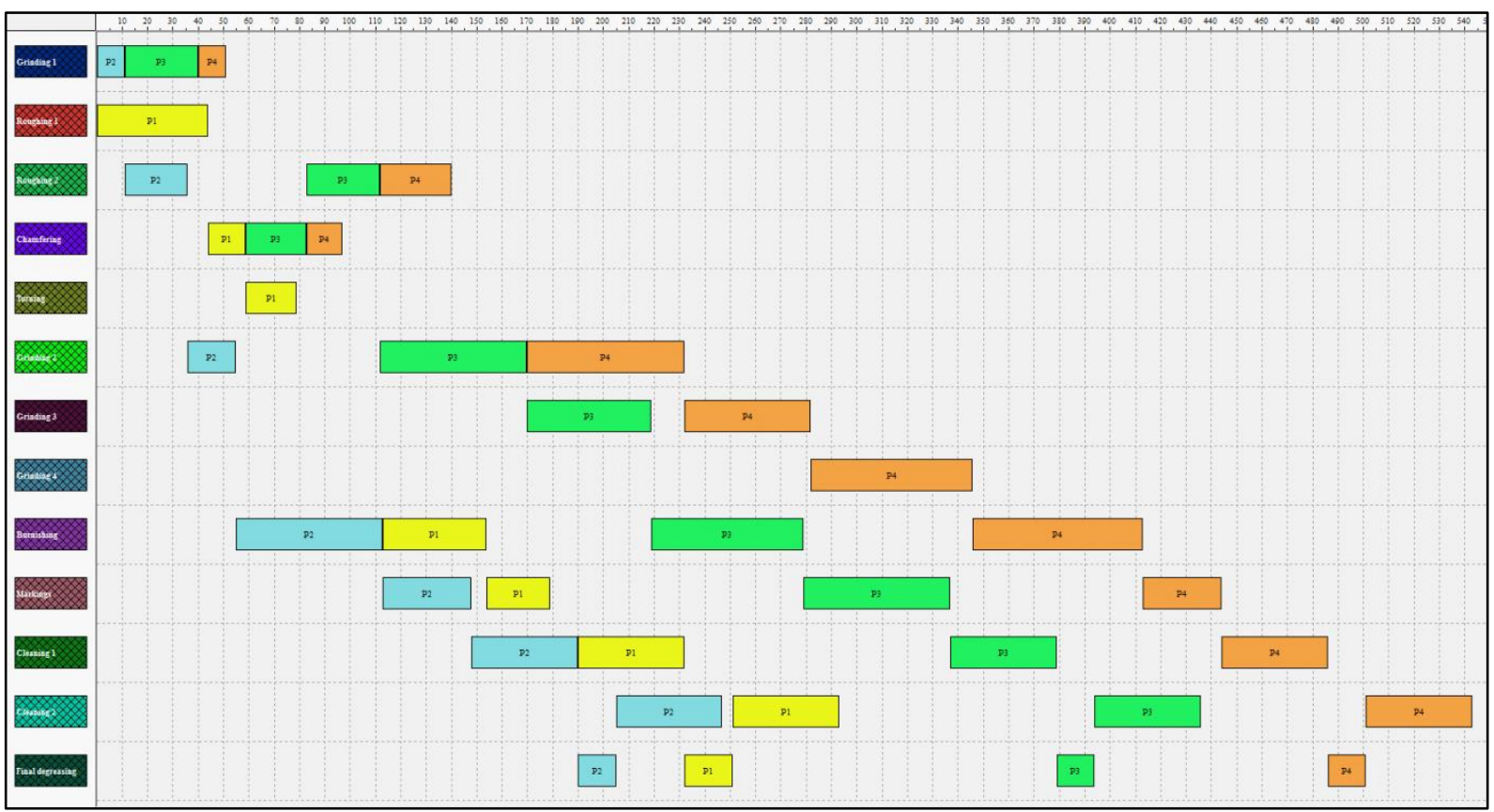

Figure 4: Gantt charts - SPT rule.

When applying the second FCFS rule, in contrast to applying the SPT rule, the difference lies in the arrangement only during the Chamfering operation, where P3 is the first part to be machined followed by P3 and P4 (Fig. 5). In this case, shorter production time is obtained when applying the first rule but the preference of task processing is violated. The total production time when applying the second rule accounts for 524 seconds with a total $T_{\max }$ delay of 98. As with the first rule, three late jobs have been recorded.

Based on the requirement of minimum idle time between workstations, it is necessary to ensure the maximum possible continuity of the production process. In this case, the MS rule was applied with the maximum job completion $C_{\max }$ time reaching 534 seconds with a delay of 108 seconds (Fig. 6). However, the total flow time is the largest among all the applied rules so far. As with previous rule applications, three late jobs have been recorded. 


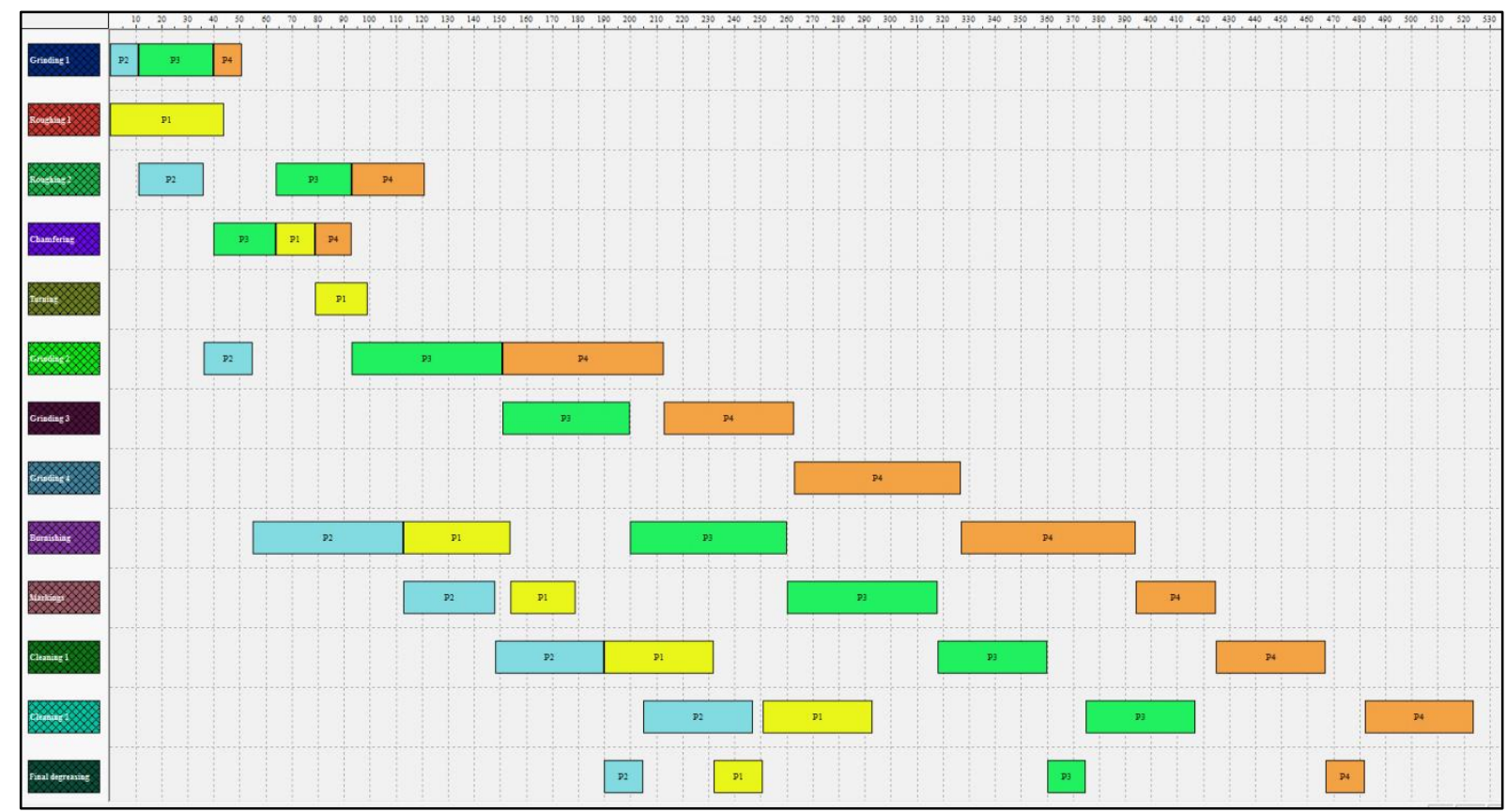

Figure 5: Gantt charts - FCFS rule.

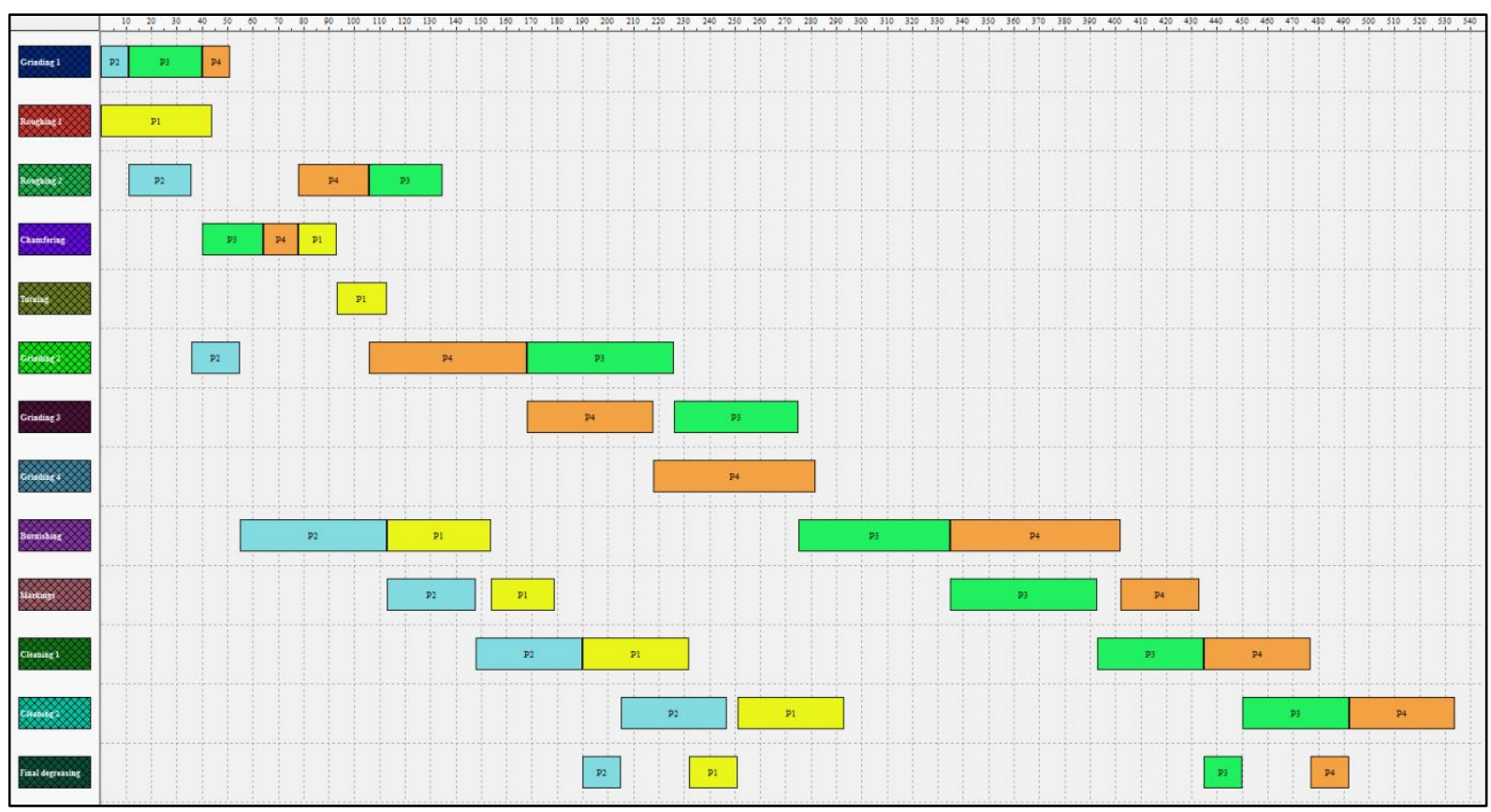

Figure 6: Gantt charts - MS rule.

If the slack time is relatively small and its importance factor is relatively large then it is important to use the $\mathrm{CR}$ rule. Once again in this application there occurs a change in order of parts machining at the Chamfering workplace. This change is not very satisfactory since the overall makespan $C_{\max }$ has increased to 566 seconds with the highest increase in processing delay of up to 140 seconds (Fig. 7). 


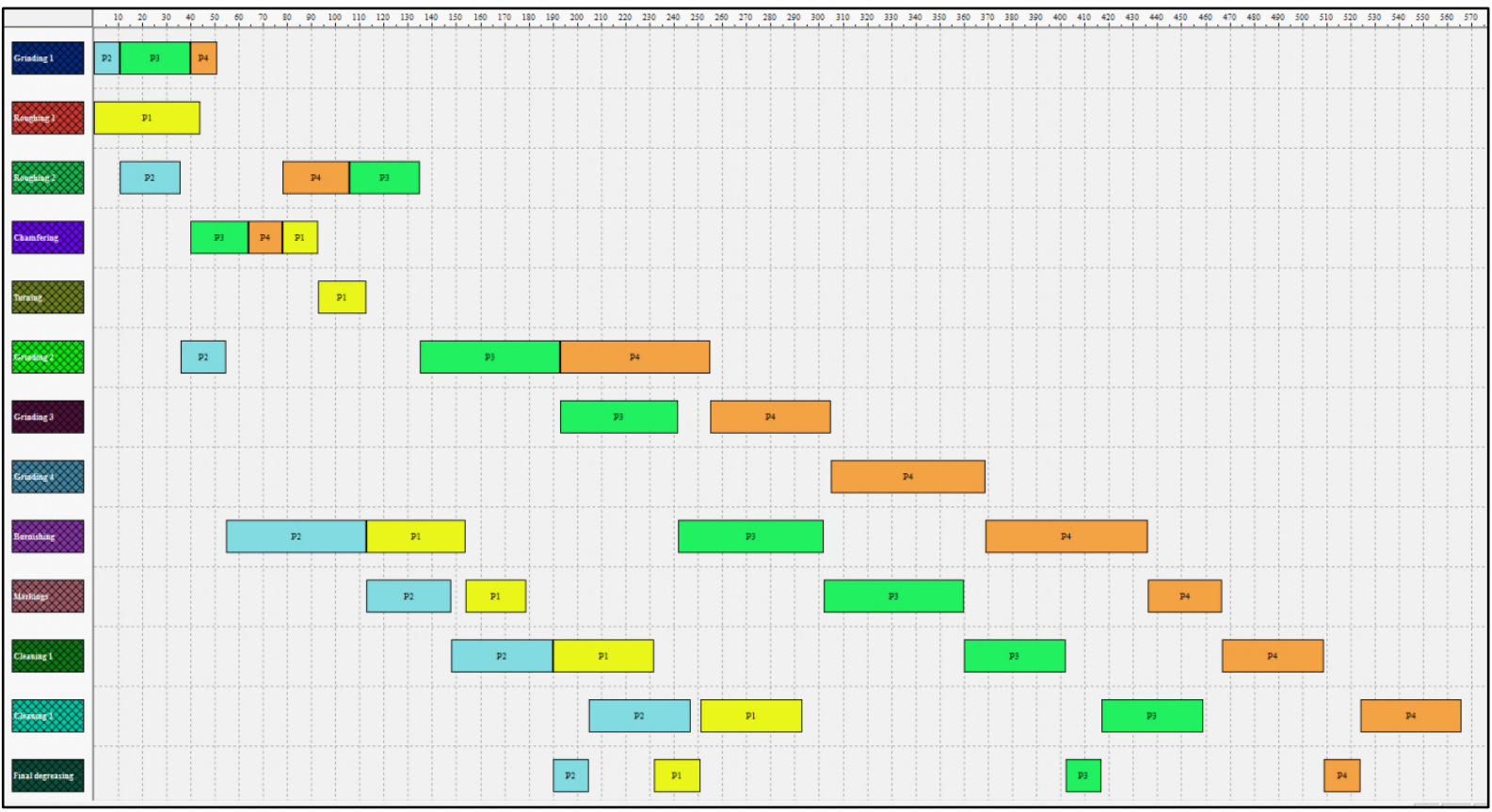

Figure 7: Gantt charts $-\mathrm{CR}$ rule.

The last applied LPT rule organized the manufacturing process with the greatest changes over the previous rules. This rule was chosen by the company to reduce production costs during material supply delays. Consequently, the larger the total production time is for the individual components the later it is possible to supply the material for further production. Under LPT, the total production time was 541 seconds for up to four late jobs (Fig. 8). The total delay lasted 294 seconds.

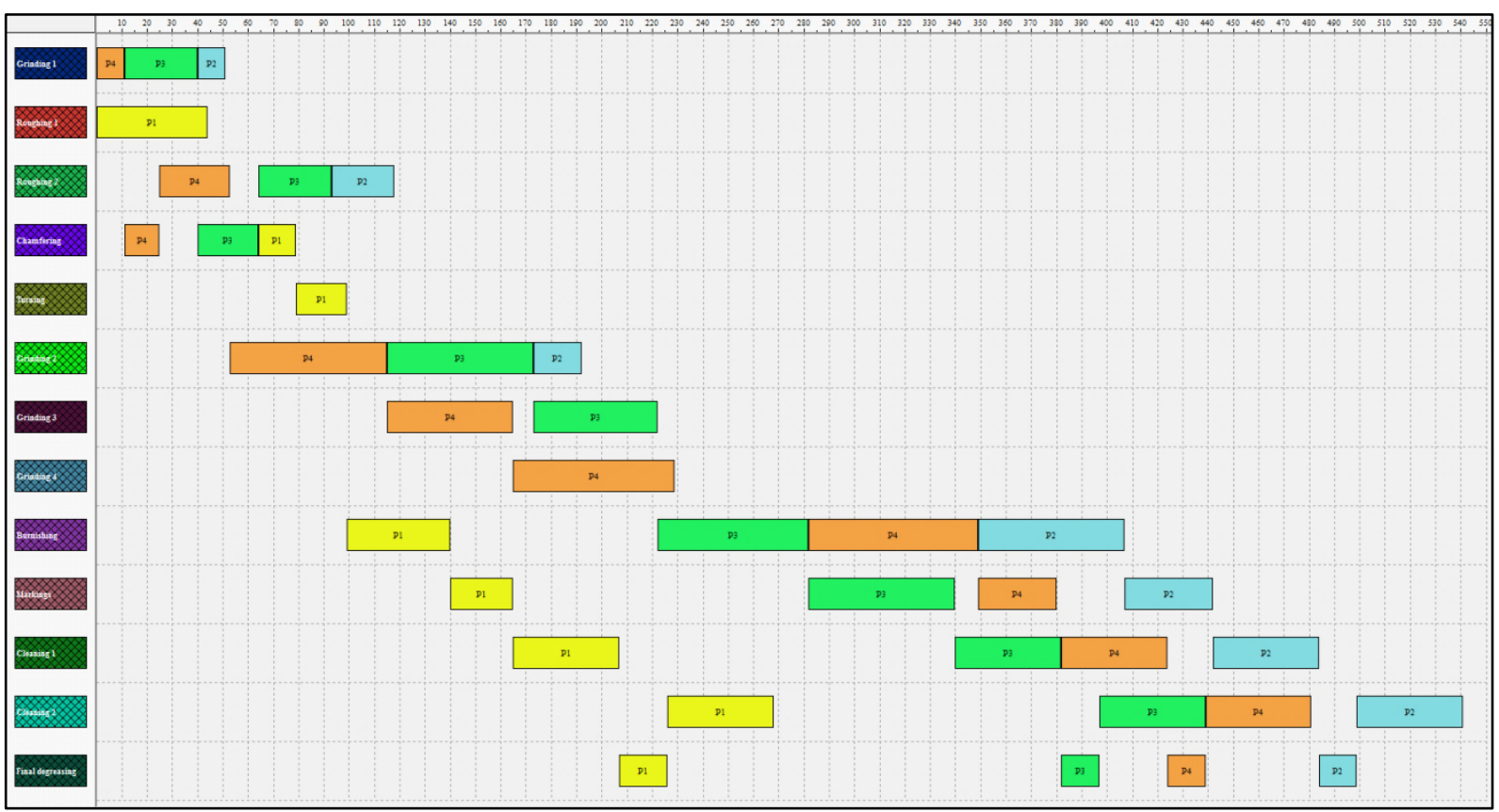

Figure 8: Gantt charts - LPT rule.

The overall results of the rules applied are presented in Fig. 9 with graphical representation using the objective chart (Fig. 10). The values $C_{\max }, T_{\max }$ and $\sum U_{i}$ from all of the presented values are important and decisive. 


\begin{tabular}{|c|c|c|c|c|c|c|c|c|c|}
\hline \multicolumn{8}{|l|}{ (1) Log Book - Seqs } & \multicolumn{2}{|c|}{\begin{tabular}{|l|l|}
0 & 0 \\
\end{tabular}} \\
\hline \multicolumn{10}{|l|}{ 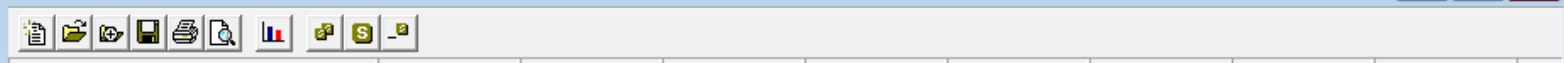 } \\
\hline Schedule & Time & $c_{\text {sex }}$ & $T_{\text {sex }}$ & $\Sigma U_{j}$ & $\Sigma C_{j}$ & $\Sigma T_{j}$ & $\Sigma w_{j} C_{j}$ & $\Sigma w_{I} T_{j}$ & \\
\hline$\overline{C R}$ & 1 & 566 & 140 & 3 & 1565 & 238 & 4428 & 764 & \\
\hline FCFS & 1 & 524 & 98 & 3 & 1481 & 154 & 4134 & 470 & \\
\hline LPT & 1 & 541 & 294 & 4 & 1729 & 402 & 4591 & 927 & \\
\hline MS & 1 & 534 & 108 & 3 & 1566 & 239 & 4399 & 735 & \\
\hline 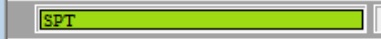 & 1 & 543 & 117 & 3 & 1519 & 192 & 4267 & 603 & \\
\hline
\end{tabular}

Figure 9: Log Book of applied rules.

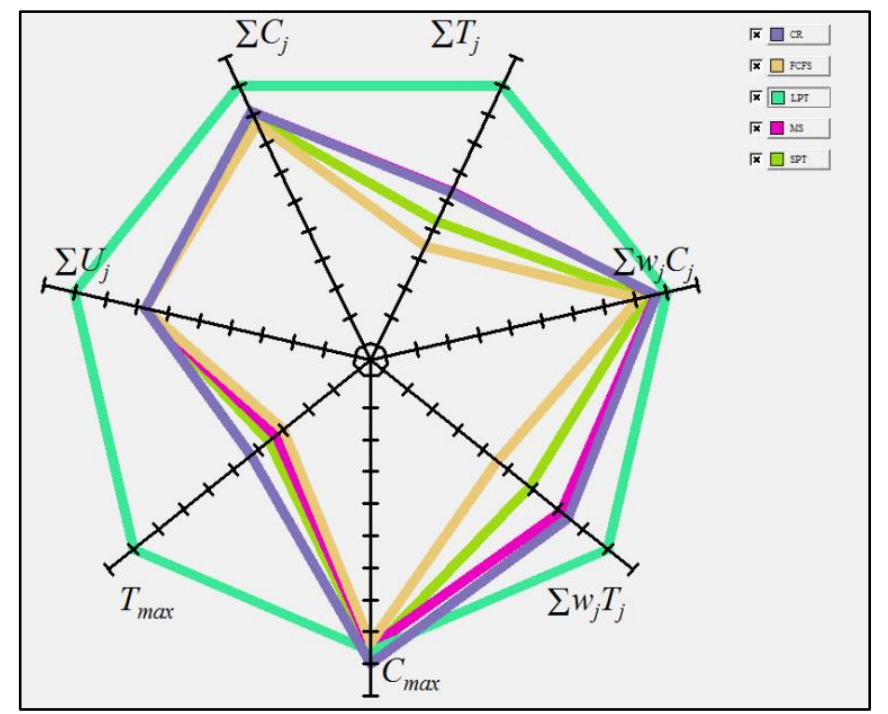

Figure 10: Objective chart - graphical interpretation of the results.

Based on Gantt charts created by means of scheduling software, the models were designed using Witness simulation tool to verify the applied decision rules and their subsequent technical and economic evaluation.

Verification of the simulation model assembly was performed by monitoring the order of individual components machining on the given machines and also through the total production time. Five verification models were compiled according to each rule. Table II shows the total production time achieved in Witness program when applying individual rules.

Table II: Total production time - Witness program.

\begin{tabular}{|l|c|}
\hline Dispatching rule & Production time [s] \\
\hline SPT rule & 543 \\
\hline FCFS rule & 524 \\
\hline MS rule & 534 \\
\hline CR rule & 566 \\
\hline LPT rule & 541 \\
\hline
\end{tabular}

In addition to the total production time, the manufacturing time of the individual components was also monitored. Partial component production time for each rule is shown in Fig. 11.

From the models that were created and in addition to the total production time and partial production time of the individual components, the individual machines load has been also monitored and recorded in the graphs below. Based on these charts, it can be stated that the load and hence the inactivity of the machines in all cases reach values differing in tenths. Fig. 12 presents graphical results of machine load and inactivity after applying heuristic rules. 


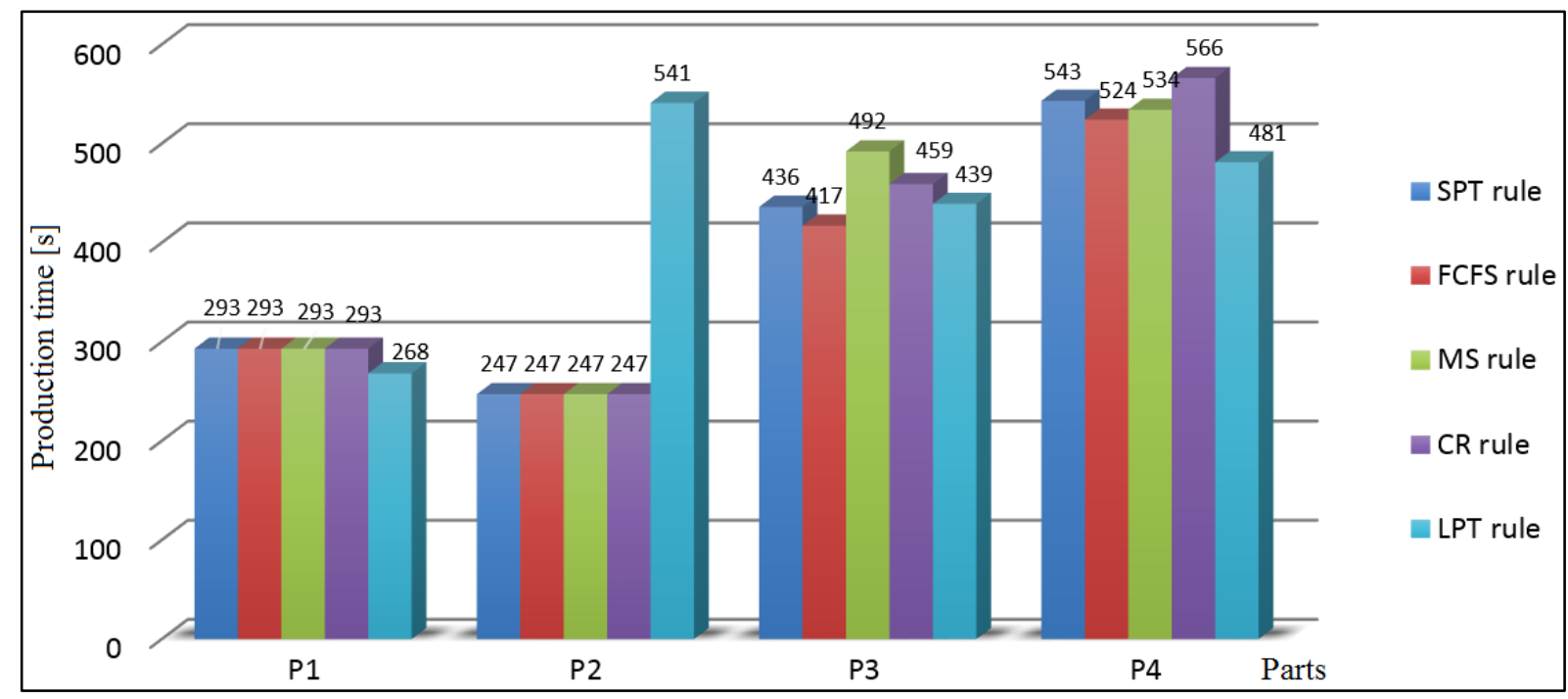

Figure 11: Partial component production time for each rule.
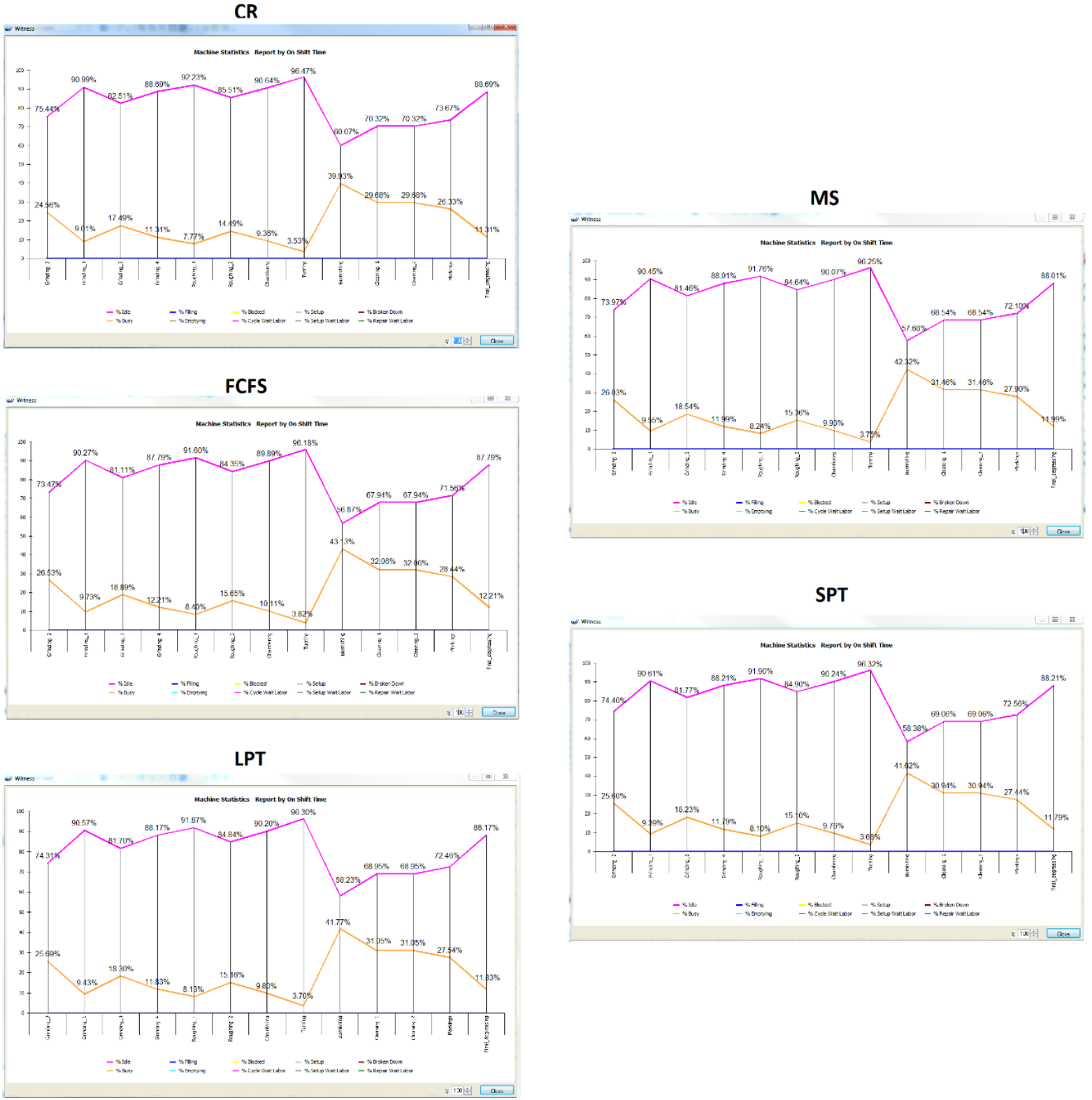

Figure 12: Application of heuristic rules in the Witness - Machine statistics. 
Having verified the simulation model, the costs that can only be assessed using Witness simulation software have been estimated. The Table III sets out the input values for the subsequent implementation of the economic assessment ensuring the economic efficiency of the production process.

Table III: Input data for economic evaluation [€].

\begin{tabular}{|l|c|c|c|c|}
\hline Operation & fixed used & busy use & idle use & use per operation \\
\hline Grinding_1 & 0.35 & 0.20 & 0.30 & 0.50 \\
\hline Grinding_2 & 0.50 & 0.80 & 0.40 & 0.20 \\
\hline Grinding_3 & 0.70 & 0.60 & 0.10 & 0.50 \\
\hline Grinding_4 & 0.60 & 0.70 & 0.80 & 0.40 \\
\hline Roughing_1 & 0.40 & 0.30 & 0.35 & 1.00 \\
\hline Roughing_2 & 0.45 & 0.25 & 0.8 & 0.15 \\
\hline Chamfering & 0.30 & 0.10 & 0.25 & 0.30 \\
\hline Turning & 0.25 & 0.40 & 0.60 & 1.00 \\
\hline Burnishing & 0.90 & 0.70 & 0.40 & 0.90 \\
\hline Cleaning_1 & 1.20 & 0.85 & 0.55 & 0.35 \\
\hline Cleaning_2 & 1.20 & 0.50 & 0.75 & 0.25 \\
\hline Markings & 1.10 & 0.45 & 0.85 & 0.80 \\
\hline Final_degreasing & 0.70 & 0.35 & 0.20 & 0.50 \\
\hline
\end{tabular}

The above costs were defined for one component in Euros per production machine. As with total production time, partial time, machine load and inactivity, the economic indicators were monitored in all five models. Table IV shows total machine costs when implementing individual rules.

Table IV: Total machine costs.

\begin{tabular}{|c|c|c|c|c|}
\hline Rule & Fixed & By Use & By Quantity & Total \\
\hline CR & $4.895,90 €$ & $3.654,65 €$ & $18,05 €$ & $8.568,60 €$ \\
\hline LPT & $4.679,65 €$ & $3.495,90 €$ & $18,05 €$ & $8.193,60 €$ \\
\hline SPT & $4.696,95 €$ & $3.508,60 €$ & $18,05 €$ & $8.223,60 €$ \\
\hline MS & $4.619,10 €$ & $3.451,45 €$ & $18,05 €$ & $8.088,60 €$ \\
\hline FCFS & $4.532,60 €$ & $3.363,95 €$ & $18,05 €$ & $7.914,60 €$ \\
\hline
\end{tabular}

Having applied both planning and simulation software, the results were evaluated in a global perspective for each condition. The obtained results and their evaluation are presented in the following subchapter of the article.

\section{RESULTS AND DISCUSSION}

Within the overall assessment of the production process, it is necessary to follow the total load for individual machines from the technical as well as economic point of view. Table $\mathrm{V}$ shows the machine load after applying the heuristic rules.

The Table $\mathrm{V}$ shows that the minimum machine load accounts for $3.53 \%$ for turning operations. This low load is caused by the fact that only one component is being machined once on the machine. One of the options to maximize machine load is to ensure machining of other parts on this machine by obtaining new orders for machining by turning technology with respect to the primary production process, adherence to logistics and thus ensuring the economy of the overall production process, either primary or secondary. Since the maximum machine load is not half of the possible value, it is appropriate to apply the design to all 
machines and thus to provide a secondary production process in the production plant, thereby maximizing machine load and ensuring greater economic efficiency.

Table V: Busy state of machines.

\begin{tabular}{|lc|c|c|c|c|}
\cline { 2 - 6 } \multicolumn{1}{c|}{} & \multicolumn{5}{c|}{ Busy [\%] } \\
\hline Operation & CR & LPT & SPT & MS & FCFS \\
\hline Grinding_2(1) & 24.56 & 25.69 & 25.6 & 26.03 & 26.53 \\
\hline Grinding_1(1) & 9.01 & 9.43 & 9.39 & 9.55 & 9.73 \\
\hline Grinding_3(1) & 17.49 & 18.3 & 18.23 & 18.54 & 18.89 \\
\hline Grinding_4(1) & 11.31 & 11.83 & 11.79 & 11.99 & 12.21 \\
\hline Roughing_1(1) & 7.77 & 8.13 & 8.1 & 8.24 & 8.4 \\
\hline Roughing_2(1) & 14.49 & 15.16 & 15.1 & 15.36 & 15.65 \\
\hline Chamfering(1) & 9.36 & 9.8 & 9.76 & 9.93 & 10.11 \\
\hline Turning(1) & 3.53 & 3.7 & 3.68 & 3.75 & 3.82 \\
\hline Burnishing(1) & 39.93 & 41.77 & 41.62 & 42.32 & 43.13 \\
\hline Cleaning_1(1) & 29.68 & 31.05 & 30.94 & 31.46 & 32.06 \\
\hline Cleaning_2(1) & 29.68 & 31.05 & 30.94 & 31.46 & 32.06 \\
\hline Markings(1) & 26.33 & 27.54 & 27.44 & 27.9 & 28.44 \\
\hline Final_degreasing(1) & 11.31 & 11.83 & 11.79 & 11.99 & 12.21 \\
\hline
\end{tabular}

The second observed parameter and practical requirement is to track the total production time after applying the heuristic rules. As it is shown in Table III, the minimum manufacturing time was reached after applying the FCFS rule of 524 seconds and the maximum manufacturing time was reached when applying the $\mathrm{CR}$ rule.

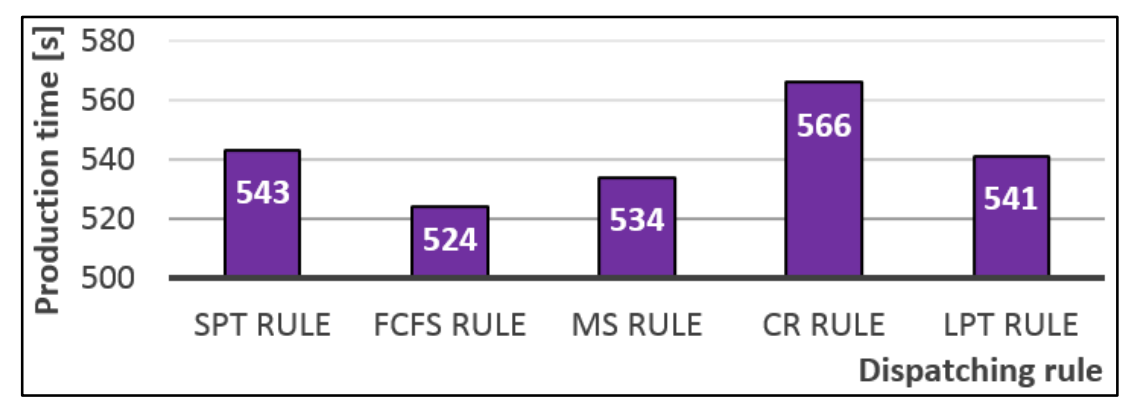

Figure 13: Production time after the application of the rules

To ensure economic efficiency, the total cost, with the input values shown in Table V, was also surveyed. After applying the individual rules, the total cost is shown in Fig. 14.

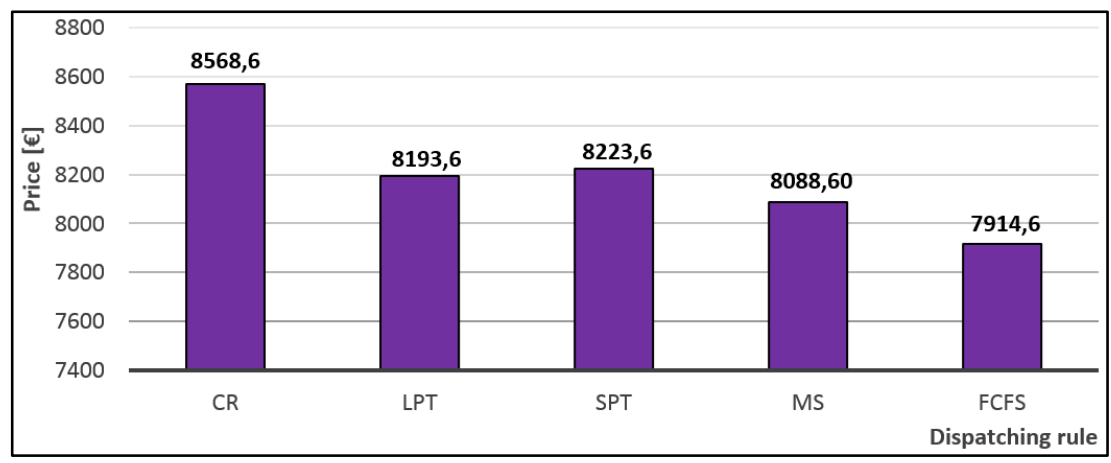

Figure 14: Economic of production process after the application of the rules. 
Based on the above-mentioned chart of total costs after the implementation of the decision-making rules in the production process, it can be stated that the total machine costs are the highest when applying the CR rule. The lowest costs were recorded in the production process after the FCFS rule was applied.

In the global assessment of overall research for the conditions set out in practice, the following conclusions can be made:

- In order to ensure a minimum production time (524 seconds), the best option is to apply the FCFS rule to the existing production system in which the first component to be used is the one that first enters the production process.

- To ensure maximum machine load, it is appropriate to apply the FCFS rule, after which the average machine load reached $19.48 \%$; due to the low average value it would be appropriate to apply the proposed solution to the implementation of the secondary production process at the workplace.

- For the provision of limited machine costs (practical requirement for maximum of $€ 8000$ ), it is also appropriate to apply the FCFS rule resulting in total machine costs of $€ 7914.60$.

Based on these conclusions, it could be stated that the most appropriate application for the given manufacturing process is to use the FCFS rule in terms of ensuring technical and economic efficiency.

In the global assessment of the overall research for the general conditions resulting from the research, the following conclusions can be made:

- Creation of verification models in the simulation program based on background material from the scheduling program.

- The information provided should be used in planning and management of production process.

- Saving time and costs as a result of using planning and simulation tool at the same time. Having linked both simulation and planning programs, the rapid possibility of designing optimum production time and ensuring economic efficiency for the manufacturing process in general is obvious.

- More optimizations can be made to the created models saving both time and money for manufacturing companies.

\section{CONCLUSION}

Nowadays, every manufacturing enterprise needs to produce the highest quality products in the shortest possible time meeting all the requirements of the customer [21, 22]. To meet the practical needs, planning has helped since ancient times. Production scheduling plays a vital role in planning and operation of a manufacturing system [23]. The Job Shop Scheduling Problem (JSSP) is one of the most general and difficult of all traditional scheduling combinatorial problems with considerable importance in industry [24]. Today, we can observe much pressure on enterprises from the market, the competition and the customer $[25,26]$. For this reason, various planning or simulation programs are becoming increasingly important. Such programs enable various companies to handle difficult situations in production processes. The basic idea of our investigation was the requirement to ensure the optimal solution for the production process regarding both time and economy.

The requirement was solved by simulation due to non-recovery of the running production process. The original benefit lies in linking both planning and simulation software. Planning software provides material flow optimization in terms of time efficiency and the resulting solutions are then verified using simulation software that optimizes material flow in terms of economic efficiency. From a practical point of view, this paper can be viewed as an important presentation of linking both simulation and planning software programs that can be used by 
every manufacturing company that needs to optimize its existing or newly created production process taking into account both time and economic aspects.

\section{ACKNOWLEDGEMENT}

This work was supported by the research grants VEGA 1/0492/16 - Research of the Possibilities of Elimination Deformations of the Thin Components with the Use of High Speed Machining and KEGA 025TUKE-4/2018 - Transfer of new approaches of teaching technology-oriented courses and implementation of teaching in practical terms for current needs of the Slovak industry.

\section{REFERENCES}

[1] Rashidi, H. (2017). Discrete simulation software: a survey on taxonomies, Journal of Simulation, Vol. 11, No. 2, 174-184, doi:10.1057/jos.2016.4

[2] Ali, N. B.; Petersen, K.; Wohlin, C. (2014). A systematic literature review on the industrial use of software process simulation, Journal of Systems and Software, Vol. 97, 65-85, doi: $10.1016 / j . j s s .2014 .06 .059$

[3] Markt, P. L.; Mayer, M. H. (1997). WITNESS simulation software: a flexible suite of simulation tools, Proceedings of the $29^{\text {th }}$ Winter Simulation Conference (WSC'97), 711-717, doi: $10.1145 / 268437.268613$

[4] Zhou, R.; Zhao, H.; Chen, K. (2011). Production logistics system simulation about automobile parts shop based on Witness and E-factory, Advanced Materials Research, Vols. 291-294, 31753179, doi:10.4028/www.scientific.net/AMR.291-294.3175

[5] Xiao, Y.; Li, Y. Y.; Zhou, K. Q. (2012). Parameter optimization of Kanban production system for an engine assembly workshop based on Witness, Advanced Materials Research, Vol. 382, $252-$ 255, doi:10.4028/www.scientific.net/AMR.382.252

[6] Holík, J.; Landryová, L. (2013). Universal simulation model in Witness software for verification and following optimization of the handling equipment, Emmanouilidis, C.; Taisch, M.; Kiritsis, D. (Eds.), Advances in Production Management Systems. Competitive Manufacturing for Innovative Products and Services, APMS 2012, Vol. 397, Springer, Berlin, 445-451, doi:10.1007/978-3-642-40352-1_56

[7] Chen, Y. H.; Li, H. F.; Qiu, F. S.; Xu, J.; Feng, Z. T. (2014). Study on the product development process based on WITNESS Simulation, Applied Mechanics and Materials, Vol. 577, 1292-1295, doi:10.4028/www.scientific.net/AMM.577.1292

[8] Dyntar, J.; Strachotova, D. (2015). Witness dynamic simulation for supply chain design and optimisation, Proceedings of the $26^{\text {th }}$ International-Business-Information-ManagementAssociation Conference: Innovation management and sustainable economic competitive advantage: from regional development to global growth, 346-351

[9] Zwolińska, B.; Smolińska, K. (2015). Use of Witness simulation for improving the continuity of the flow, Conference Proceedings of the Carpathian Logistics Congress 2015, 485-490

[10] Ma, L.; Ma, M.; Ma, C.; Deng, J.; Liu, X.; Zhao, L. (2016). Simulation and optimization study on layout planning of plant factory based on WITNESS, International Journal of Security and its Applications, Vol. 10, No.5, 275-282

[11] Cotet, C. E.; Popa, C. L.; Enciu, G.; Popescu, A.; Dobrescu, T. (2016). Using CAD and flow simulation for educational platform design and optimization, International Journal of Simulation Modelling, Vol. 15, No. 1, 5-15, doi:10.2507/IJSIMM15(1)1.310

[12] Wang, Y.; Yang, O. (2017). Research on industrial assembly line balancing optimization based on genetic algorithm and Witness simulation, International Journal of Simulation Modelling, Vol. 16, No. 2, 334-342, doi:10.2507/IJSIMM16(2)CO8

[13] Jaffrey, V.; Mohamed, N. M. Z. N.; Rose, A. N. M. (2017). Improvement of productivity in low volume production industry layout by using Witness simulation software, IOP Conference Series: Materials Science and Engineering, Vol. 257, Paper 012030, doi:10.1088/1757$\underline{899 X / 257 / 1 / 012030}$ 
[14] Balog, M.; Dupláková, D.; Szilágyi, E.; Mindas, M.; Knapčíková, L. (2016). Optimization of time structures in manufacturing management by using scheduling software Lekin, TEM Journal, Vol. 5, No. 3, 319-323, doi:10.18421/TEM53-11

[15] Forrai, M. K.; Kulcsár, G. (2017). A new scheduling software for supporting automotive component manufacturing, Jármai, K.; Bolló, B. (Eds.), Vehicle and Automotive Engineering, Springer, Cham, 257-274, doi:10.1007/978-3-319-51189-4_25

[16] Zhang, H.; Liu, S.; Moraca, S.; Ojstersek, R. (2017). An effective use of hybrid metaheuristics algorithm for job shop scheduling problem, International Journal of Simulation Modelling, Vol. 16, No. 4, 644-657, doi:10.2507/IJSIMM16(4)7.400

[17] Amariei, O. I.; Hamat, C. O.; Coman, L.; Burian, R. (2013). Minimizing makespan in job shop production using a network approach, Robotica \& Management, Vol. 18, No. 2, 39-41

[18] Gracanin, D.; Lalic, B.; Beker, I.; Lalic, D.; Buchmeister, B. (2013). Cost-time profile simulation for job shop scheduling decisions, International Journal of Simulation Modelling, Vol. 12, No. 4, 213-224, doi:10.2507/IJSIMM12(4)1.237

[19] Yamada T; Nakano R. (1997). Job-shop scheduling, Zalzala, A. M. S.; Fleming, P. J. (Eds.), Genetic algorithms in engineering systems, IEE Control Engineering series 55, The Institution of Electrical Engineers, London, 134-160

[20] Pinedo, M. (2010). Scheduling: Theory, Algorithms, and Systems. New York University, New York

[21] Lehocká, D.; Hlavatý, I.; Hloch, S. (2016). Rationalization of material flow in production of semitrailer frame for automotive industry, Technical Gazette, Vol. 23, No. 4, 1215-1220, doi:10.17559/TV-20131113100109

[22] Petru, J.; Zlamal, T.; Cep, R.; Pavlica, M. (2014). The using of elements of lean production to increase efficiency and competitiveness of organizations in the engineering industry, Fourth International Conference on Industrial Engineering and Operations Management, 802-811.

[23] Rathinam, B.; Govindan, K.; Neelakandan, B.; Raghavan, S. S. (2015). Rule based heuristic approach for minimizing total flow time in permutation flow shop scheduling, Technical Gazette, Vol. 22, No. 1, 25-32, doi:10.17559/TV-20130704132725

[24] Janes, G.; Perinic, M.; Jurkovic, Z. (2017). Applying improved genetic algorithm for solving job shop scheduling problems, Technical Gazette, Vol. 24, No. 4, 1243-1247, doi:10.17559/TV20150527133957

[25] Zajac, J.; Beraxa, P.; Michalik, P.; Botko, F.; Pollák, M. (2016). Simulation of weld elbows hot forming process, International Journal of Modeling and Optimization, Vol. 6, No. 2, 77-80, doi:10.7763/IJMO.2016.V6.507

[26] Kočiško, M.; Novák-Marcinčin, J.; Baron, P.; Dobránsky, J. (2012). Utilization of progressive simulation software for optimization of production systems in the area of small and medium companies, Technical Gazette, Vol. 19, No. 4, 983-986 